\title{
RELASIONAL DATA PENGINDERAAN JAUH DENGAN GRADASI TEMPERATUR DI TAMAN NASIONAL GUNUNG PANGRANGO
}

\author{
RELATIONAL DATA REMOTE SENSING WITH TEMPERATURE \\ GRADIENT PANGRANGO MOUNTAIN NATIONAL PARK
}

\author{
Wiweka1', Sri Handoyo², John Hendrick B², Samsul Arifin ${ }^{1}$ \\ (Diterima tanggal 15-11-2011; Disetujui tanggal 14-03-2012)
}

\begin{abstract}
ABSTRAK
Gunung adalah bentuklahan besar yang membentang di atas tanah sekitarnya, berada di wilayah yang terbatas biasanya dalam bentuk puncaknya, ketinggian tinggi di pegunungan menghasilkan iklim dingin daripada di permukaan laut, gunung di karakteristik oleh sejumlah parameter yaitu ketinggian, volume, relief, kecuraman, jarak dan kontinuitas. Iklim dingin sangat mempengaruhi ekosistem pegunungan: ketinggian yang berbeda memiliki tanaman yang berbeda dan hewan. Karena medan yang kurang ramah dan iklim, pegunungan cenderung digunakan untuk ekstraksi sumber daya dan rekreasi, seperti mendaki gunung. Parameter lingkungan memiliki fungsi dan pengaruh terhadap kehidupan komunitas. Data penginderaan jauh dapat ditransformasi menjadi nilai temperatur, tahapan transformasinya nilai dijital diubah menjadi radians kemudian dikonversi menjadi temperatur. Perlu dilakukan koreksi radiometrik, agar representasi nilai temperatur sesuai dengan kondisi sebenenarnya. Penelitian ini menggunakan data Landssat $\mathrm{ETM}+$, hasilnya menunjukkan kisaran rata-rata temperatur di puncak Taman Nasional Gunung Pangrango pada siang hari $15,92^{\circ} \mathrm{C}$ dan kecenderungan perubahan temperatur terhadap tinggi di lokasi penelitian adalah linier.
\end{abstract}

Kata Kunci: Reflektansi, Nilai Spektral, Suhu, Citra, Penginderaan Jauh

\begin{abstract}
A mountain is a large landform that stretches above the surrounding land, located in a limited area usually in the form of peak, high altitude in the mountains produce a climate cooler than at sea level, the mountain by a number of parameters characteristic of the height, volume, relief, steepness, spacing and continuity. Cold climate greatly affect mountain ecosystems: different heights have different plants and animals. Due to the less hospitable terrain and climate, the mountains tend to be used for resource extraction and recreation, such as mountain climbing. Functions and environmental parameters have an influence on community life. Remote sensing data can be transformed into a temperature value, phase transformation radians converted to a digital value is then converted to temperature. Radiometric correction needs to be done, so that the temperature value representation in accordance with the actual conditions. This study used Landsat ETM +, the results show the average temperature range at the top of the Volcano National Park Pangrango $15.92{ }^{\circ} \mathrm{C}$ during the day and the trend toward higher temperature changes at the sites is linear.
\end{abstract}

Keywords: Reflectance, Spectral Value, Temperature, Image, Remote Sensing

\section{PENDAHULUAN}

Temperatur merupakan salah satu parameter yang sangat penting bagi lingkungan, manusia dan tumbuhan. Temperatur udara dipengaruhi oleh durasi, intensitas radiasi matahari, laju pindah panas, laju transpirasi, evaporasi, dan aktivitas biologis di sekitar lingkungan.

\footnotetext{
${ }^{1}$ LAPAN,Wiweka is with the National Institute Aeronautics and Space, Jl. R Lapan 70 Pekayon Pasar Rebo, Jakarta Timur 13710, Indonesia (corresponding author to provide phone: 62-21-8710786; fax: 62-21-8712763; e-mail: wiweka@ lapan.go.id).

2 BIG, Jl. Raya Bogor Km
} 
Lokasi penelitian dalam makalah ini di Taman Nasional Gunung Gede Pangrango (TNGGP), Jawa Barat, Indonesia, gunung ini memiliki ketinggian $\pm 3.019 \mathrm{~m}$, rata curah hujan $200 \mathrm{~mm}-400 \mathrm{~mm}$ per bulan, suhu di puncak kurang dari $18^{\circ} \mathrm{C}$, dan kelembaban antara 80\%-90\% [1,2]. Gunung ini digunakan sebagai lokasi pendakian, karena jalur pendakian memadai dan suhu mencapai $5^{\circ} \mathrm{C}$ pada musim kemarau di bulan Juni s/d September. Perubahan dan dinamika informasi suhu gunung, dapat diturunkan dengan menggunakan data penginderaan jauh, hasil dalam penelitian ini tertuangnya informasi atau gambaran pola perubahan suhu terhadap titik-titik ketinggian. Data penginderaan jauh yang digunakan adalah resolusi menengah dan untuk melakukan koreksi digunakan peta rupa bumi. Pada prinsipnya, untuk menghasilkan peta sebaran suhu, dilaksanakan dengan mengakusisi data penginderaan jauh, melakukan pengolahan citra dijital, melakukan plotting posisi ketinggian dan suhu secara kartografi ke dalam peta tematik.

\section{STUDI AREA DAN DATA}

\subsection{Study Area}

Lokasi Taman Nasional Gunung Gede Pangrango terletak di koordinat (6 ${ }^{\circ} 42^{\prime}$ '9'S , 106 56'20"E) sedangkan luasnya adalah 22.815,03 hektar, kawasan Taman Nasional ini ditutupi oleh hutan hujan tropis pegunungan.

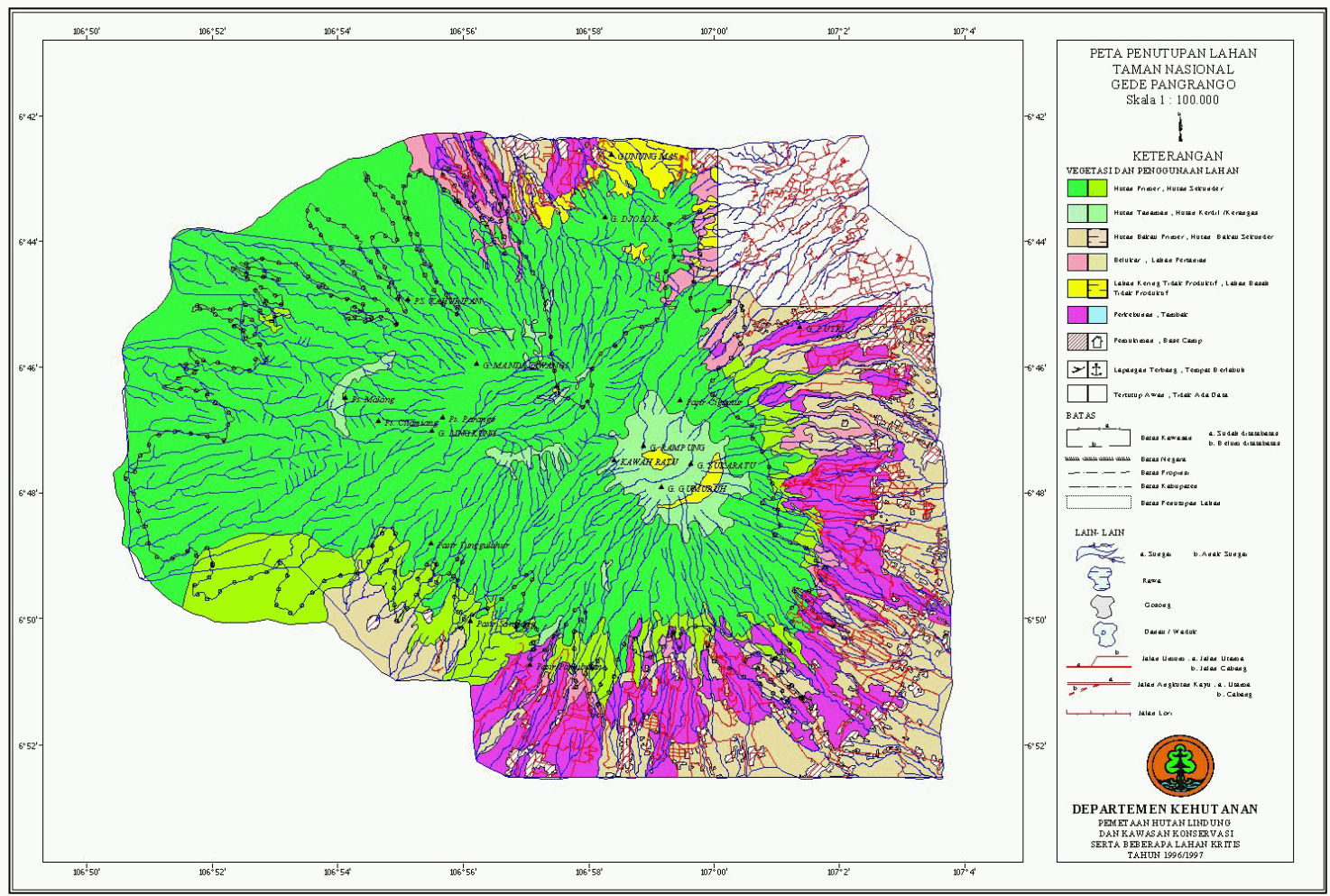

Gambar 1. Peta Tematik Taman Nasional Gede Pangrango 
Taman Nasional Gunung Gede Pangrango memiliki keanekaragaman ekosistim submontana, Montana, sub-alpin, danau, rawa, dan savanna. Dicirikan dengan adanya pohon yang besar dan tinggi seperti jamuju (Dacrycarpus imbricatus), puspa (Schima wallichii), rumput (Isachne pangerangensis), bunga eidelweis (Anaphalis javanica), violet (Viola pilosa), dan Cantigi (Vaccinium varinginaefoliuma). Satwa primata yang terancam punah dan terdapat di Taman Nasional Gunung Gede Pangrango yaitu owa (Hylobates moloch), surii (Prebytis comata), lutung budeng (Trachyithecus auratus), macan tutul (Panthera pardus melas), landak Jawa
(Hystrix brachyuran), kijang (Muntiacus muntjak), dan musang tenggorokan kuning (Martes flavigula).

\subsection{Data}

Dalam pelaksanaan penelitian ini menggunakan data antara lain : peta rupa bumi dijital Taman Nasional Gunung Gede Pangrango skala 1:25.000 dengan nomor lembar peta 1209-124,1209-142, 1209-213,1209-231 terbitan Bakosurtanal tahun 1999. Data penginderaan jauh yang digunakan citra satelit Landsat 7 ETM+ hasil perekaman tahun 2010 dengan nomor Path/Row : 122/065, hanya menggunakan band 6 untuk tujuan penelitian ini, gambar 1.

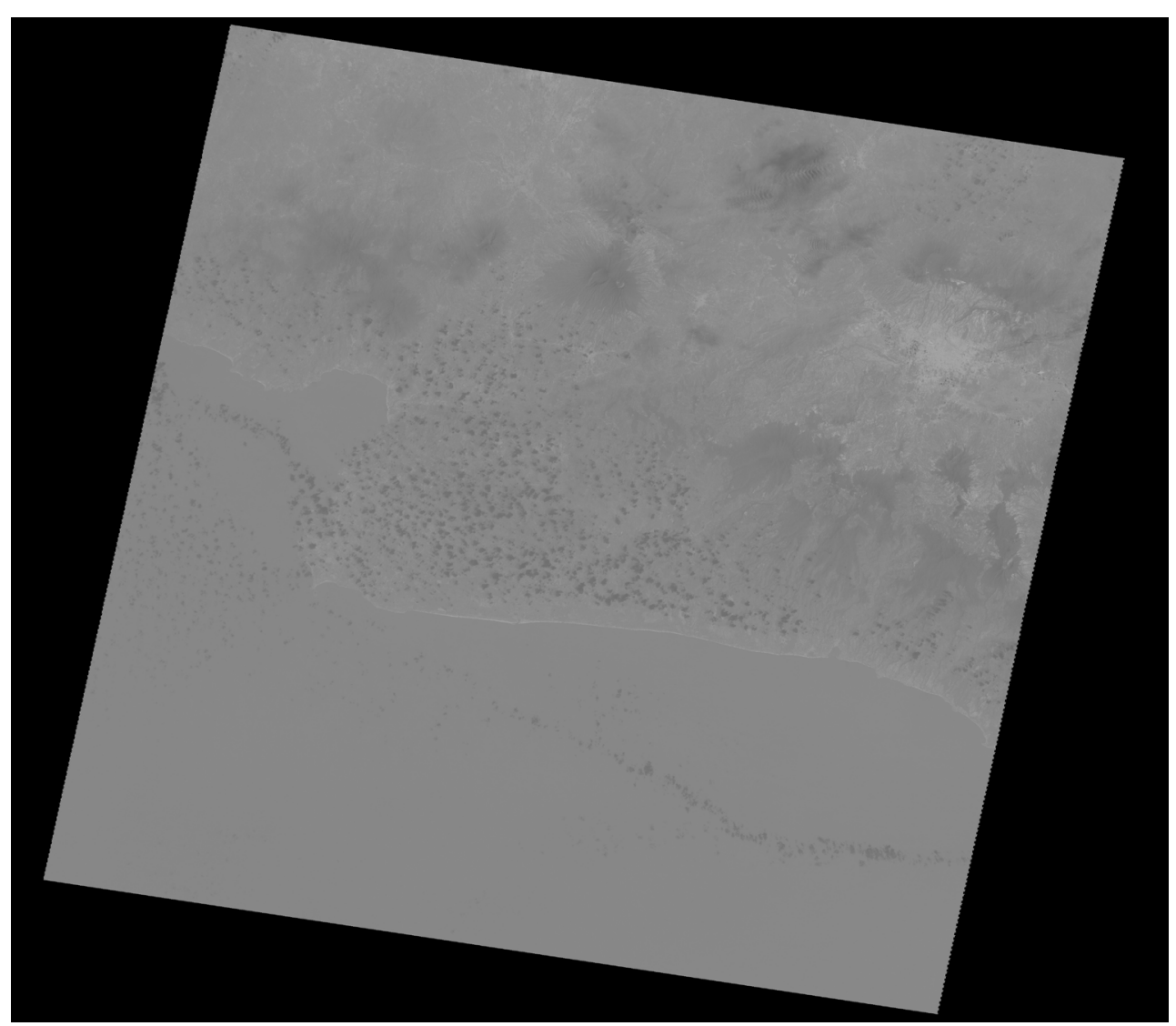

Gambar 1. Citra Taman Nasional Gunung Gede Pangrango 


\section{METODOLOGI}

Secara umum, langkah-langkah yang dilakukan dalam pelaksanaan peneltian ini dapat dilihat pada diagram akhir dibawah ini, gambar 2.

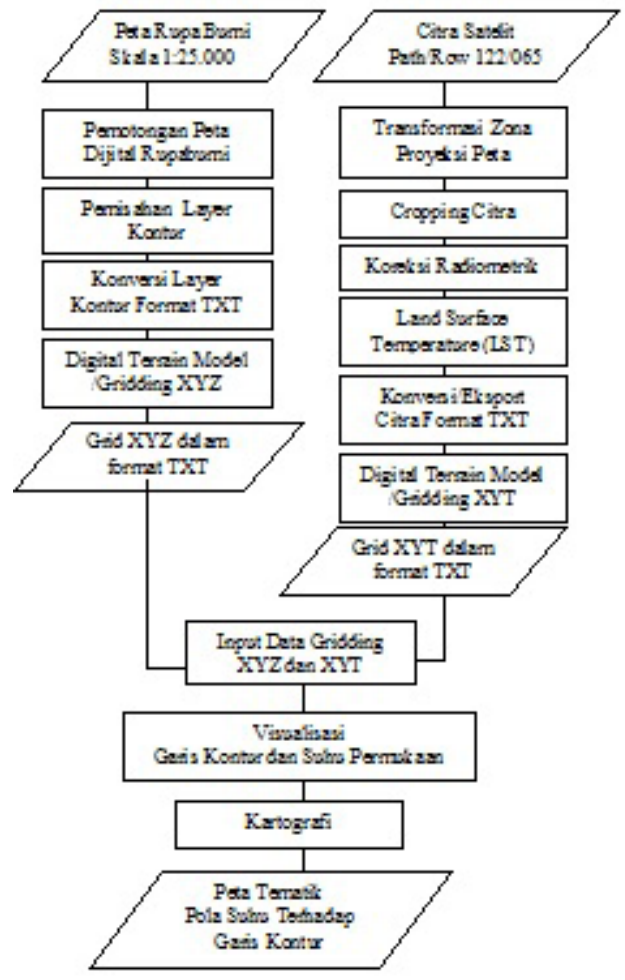

Gambar 2. Diagram Alir Penelitian Pola

Suhu Terhadap Garis Kontur.

Penjelasan Gambar 2 sebagai berikut : Karena data dasar luasannya melebihi dari cukup, maka dilakukan pemotongan dengan koordinat UTM batas pojok kiri atas $(707186.461,9260053.235)$ dan koordinat UTM pojok kanan bawah (726887.867,9239663.500), gambar 3.

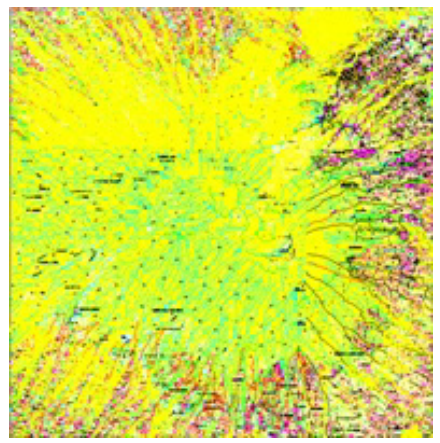

Gambar 3. Peta Rupa Bumi Taman Nasional Gede Pangrango
Langkah selanjutnya adalah memisahkan layer kontur dan elevasi dari peta rupa bumi dijital, untuk dibangun digital elevation model (DEM), gambar 4.

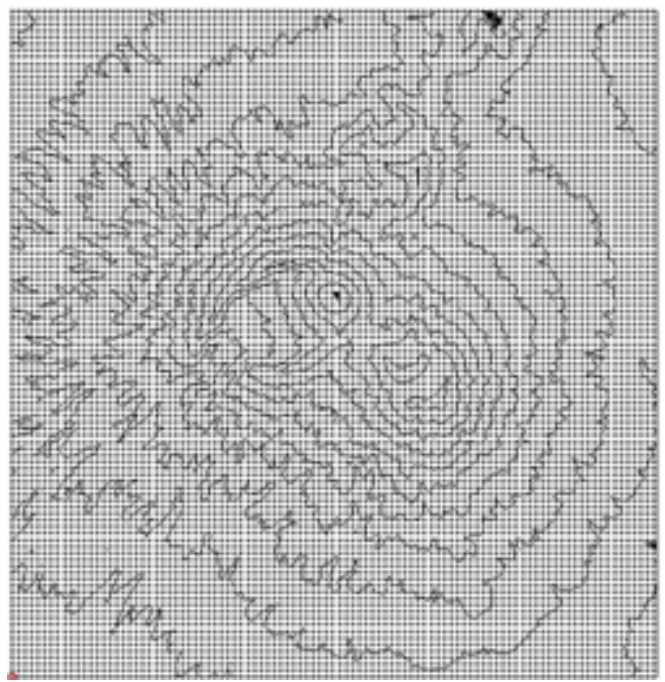

Gambar 4. Digital Elevation Model Taman Nasional Gede Pangrango

Proses pengolahan citra terhadap data landsat 7 +ETM band 6 sebagai berikut melakukan transformasi datum, pemotongan citra (gambar 5), koreksi radiometrik (gambar 6), menghitung land surface temperature, hasilnya DTM (Digital Temperature Modelling). Datum yang digunakan WGS 84 dan sistim proyeksinya adalah UTM.

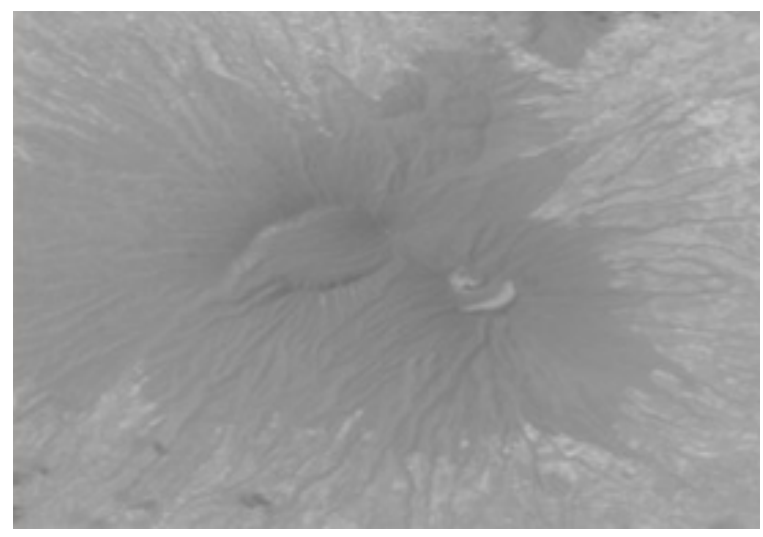

Gambar 5. Pemotongan Citra Taman Nasional Gede Pangarango 


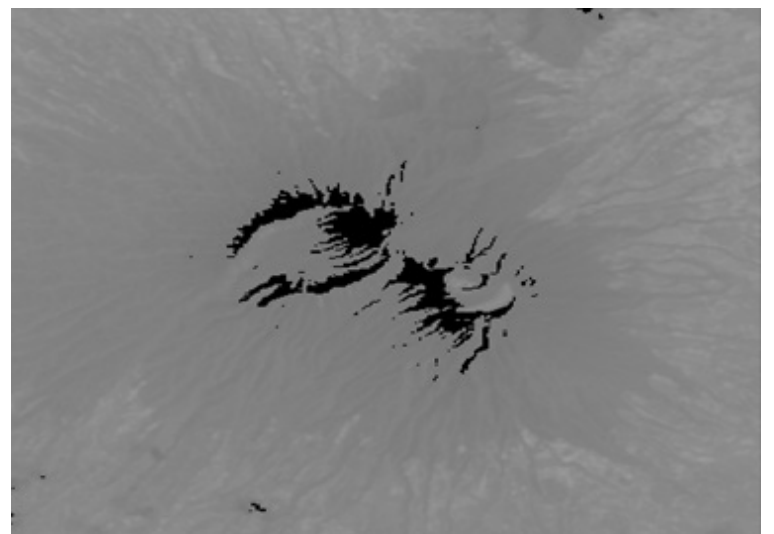

Gambar 6. Citra Terkoreksi Radiometrik

Hasil koreksi radiometrik, memberikan asumsi nilai reflektansi sesuai dengan kondisi kelas penggunaan lahan sebenarnya. Perhitungan Land Surface Temperature dilaksanakan dengan mengubah digital number menjadi radiance, kemudian dari radiance di konversi ke temperature [3].

Rumus konversi digital number (DN) ke radiance $(\mathrm{R})$ sbb:

$$
\mathrm{R}=\mathrm{K} * \mathrm{DN}+\mathrm{N} \text {. }
$$

$\mathrm{K}=$ Konstanta nilai gain $\operatorname{citra}=0,05518$

$\mathrm{N}=$ Nilai bias cahaya $=1,2378$

Menurut USGS (2001) dan Chen et.al (2001), Rumus konversi radiance (R) ke temperature (T) sbb :

$\mathrm{T}=\mathrm{K} 2 / \ln \left(\mathrm{K} 1 / \mathrm{L}_{\lambda}+1\right)$.

$\mathrm{T}=$ temperature efektif dalam Kelvin

$\mathrm{K} 1=$ konstanta satu dalam watts dengan nilai 666,09 untuk ETM+

$\mathrm{K} 2=$ konstanta dua dalam Kelvin dengan nilai 1282071 untuk ETM+

$\mathrm{L}_{\lambda}=$ radian spektral dalam watt

Langkah selanjutnya adalah membuat Digital Temperature Model (DTM), gambar 7.

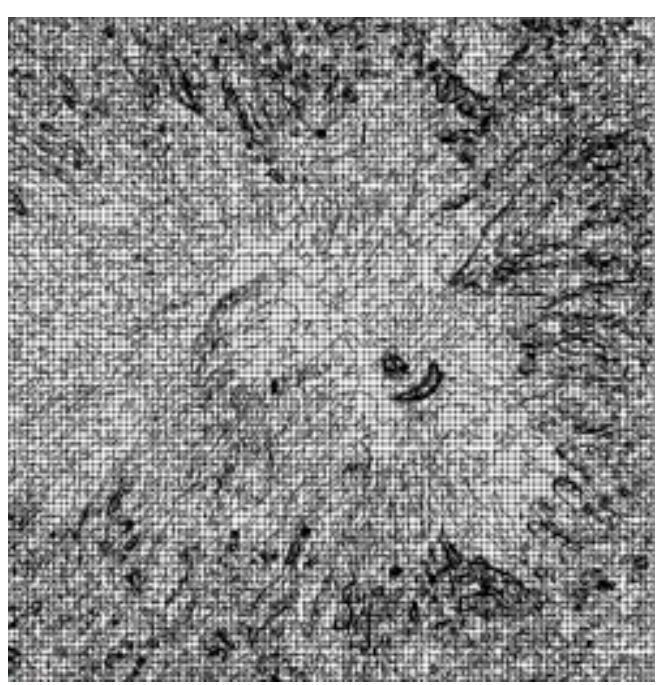

Gambar 7. Digital Temperature Model Taman Nasional Gede Pangrango

\section{HASIL DAN PEMBAHASAN}

Berdasar Digital Elevation Model dan Digital Temperature Model Taman Nasional Gunung Gede Pangrango, Kedua model tersebut dapat divisualisasikan dan dioverlay. Gambar tersebut disajikan pada Gambar 8-10

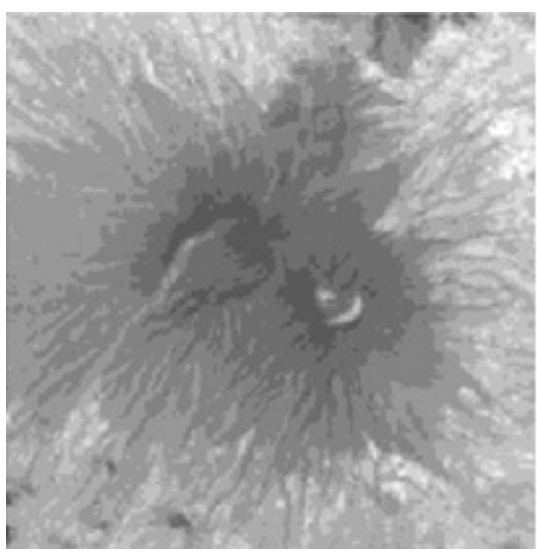

Gambar 8. Visualisasi Digital Temperature Model Taman Nasional Gunung Gede Pangrango 


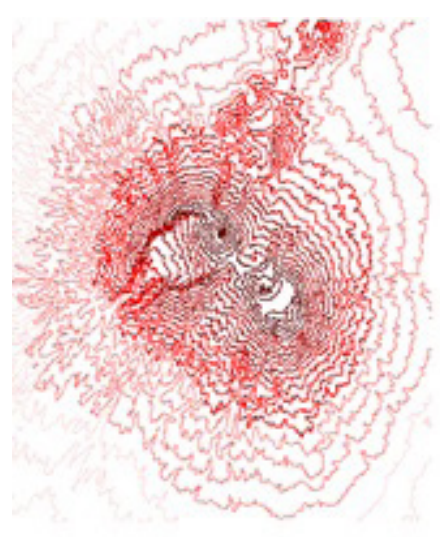

Gambar 9. Visualisasi Digital Elevation Model Taman Nasional Gunung Gede Pangrango

Dalam menvisualisasi dan mengoverlay pola sebaran suhu terhadap garis ketinggian, proses kartografi harus dilakukan agar memenuhi prinsip merancang isi peta, layout, skala dan simbol.

Hasil proses overlay ini disebut Peta Tematik Pola Sebaran Suhu Terhadap Garis Kontur Taman Nasional Gunung Gede Pangrango, disajikan dalam gambar 10

Proses interpolasi dari layer elevasi dan radiansi menjadi Digital Elevation Model dan Digital Temperature Model menggunakan metoda Krigging. Harapannya metoda interpolasi tersebut dapat memberikan ketelitian relatif cukup untuk ukuran grid $100 \mathrm{~m}$ x 100 m, dan sesuai dengan kebutuhan pengguna seperti pendaki gunung, tim SAR atau masyarakat pada umumnya

\section{Thematic Map}

Distribution Pattern Of Temperature VS. Contour Lines

National Park Of Mount Gede Pangrango

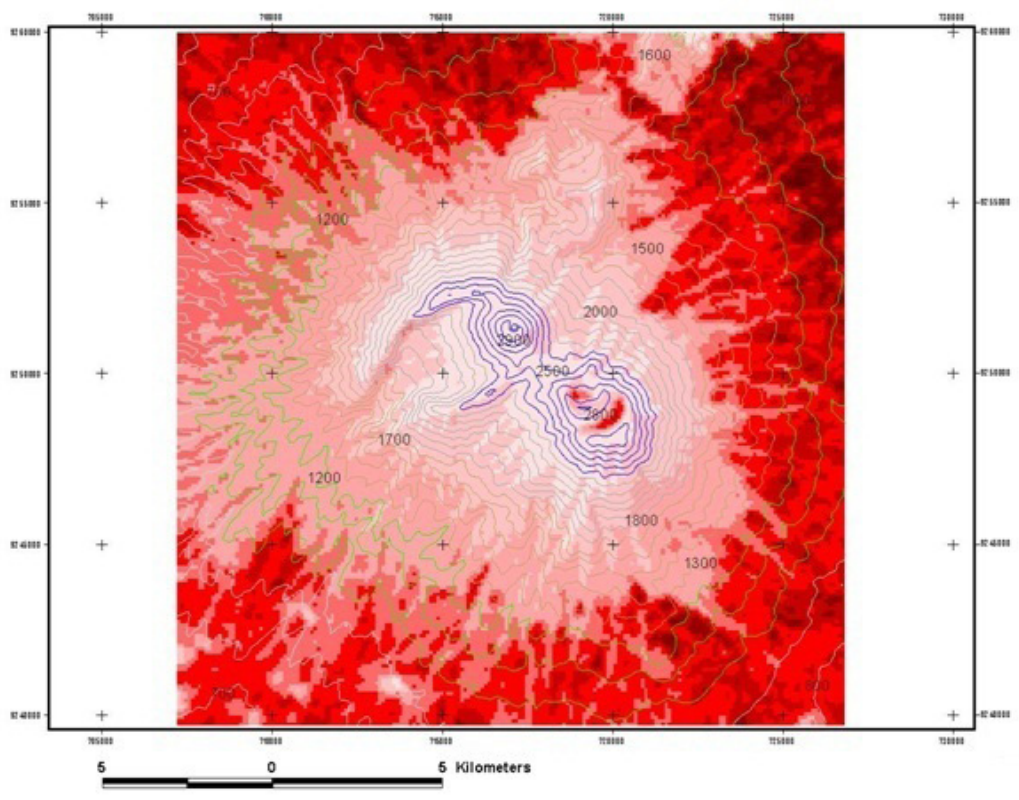

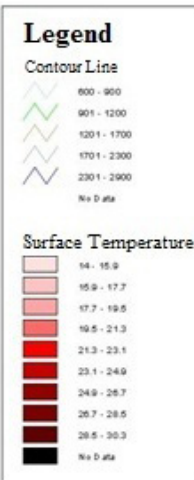

Projection System : UTM Datum : WGS84 Zone

Data Source:

Topographic Map Scale 1:25.000 (1209-124,142,213,231) Landsat 7 ETM Ban d, Path/Raw : 122/065

Gambar 10. Peta Tematik Distribusi Sebaran Suhu VS Garis Kontur. 
Dimensi yang dihasilkan di peta tematik tentang pola sebaran suhu terhadap garis ketinggian sebagai berikut menggunakan sistim proyeksi Universal Tranverse Mercator, Zona : $48 \mathrm{~S}$, skala :1:125.000, pewarnaan layer ketinggian dengan 5(lima) symbol garis dengan pola warna yang berbeda pada setiap interval kontur tertentu, dan untuk layer suhu permukaan menggunakan 9 (Sembilan) pola warna dimana setiap pola warna interval suhunya setiap $2^{\circ} \mathrm{C}$.

Berdasarkan yang tersaji di peta (Gambar 9) dan Tabel 1, bahwa pada setiap garis ketinggian memiliki suhu permukaan yang bervariasi dengan batas minimum dan maksimum suhu pada masing-masing ketinggian.

Tabel 1. Hubungan Garis Kontur Terhadap Suhu Permukaan

\begin{tabular}{|c|c|c|c|c|}
\hline Kontur & Min & Maks & Rata2 & Label \\
\hline 600 & 22.34 & 25.30 & 23.75 & $600-900$ \\
\hline 700 & 17.41 & 25.86 & 22.37 & $600-900$ \\
\hline 800 & 19.02 & 25.29 & 21.55 & $600-900$ \\
\hline 900 & 16.35 & 25.49 & 20.84 & $600-900$ \\
\hline 1000 & 17.92 & 28.05 & 21.21 & $901-1200$ \\
\hline 1100 & 16.64 & 29.43 & 21.10 & $901-1200$ \\
\hline 1200 & 16.20 & 27.42 & 20.62 & $901-1200$ \\
\hline 1300 & 15.02 & 25.62 & 19.86 & $1201-1700$ \\
\hline 1400 & 14.35 & 26.00 & 19.12 & $1201-1700$ \\
\hline 1500 & 14.19 & 23.42 & 18.39 & $1201-1700$ \\
\hline 1600 & 13.91 & 23.67 & 17.91 & $1201-1700$ \\
\hline 1700 & 15.09 & 24.30 & 17.44 & $1201-1700$ \\
\hline 1800 & 14.59 & 20.72 & 16.99 & $1701-2300$ \\
\hline 1900 & 14.58 & 20.00 & 16.62 & $1701-2300$ \\
\hline 2000 & 14.85 & 20.00 & 16.40 & $1701-2300$ \\
\hline 2100 & 14.56 & 20.06 & 16.22 & $1701-2300$ \\
\hline 2200 & 14.28 & 20.20 & 16.05 & $1701-2300$ \\
\hline 2300 & 14.33 & 18.98 & 15.89 & $1701-2300$ \\
\hline 2400 & 14.42 & 17.65 & 15.72 & $2301-2900$ \\
\hline 2500 & 14.51 & 16.93 & 15.51 & $2301-2900$ \\
\hline 2600 & 14.33 & 16.97 & 15.42 & $2301-2900$ \\
\hline 2700 & 13.98 & 20.76 & 15.65 & $2301-2900$ \\
\hline 2800 & 14.50 & 20.06 & 15.76 & $2301-2900$ \\
\hline 2900 & 14.86 & 17.85 & 15.92 & $2301-2900$ \\
\hline
\end{tabular}




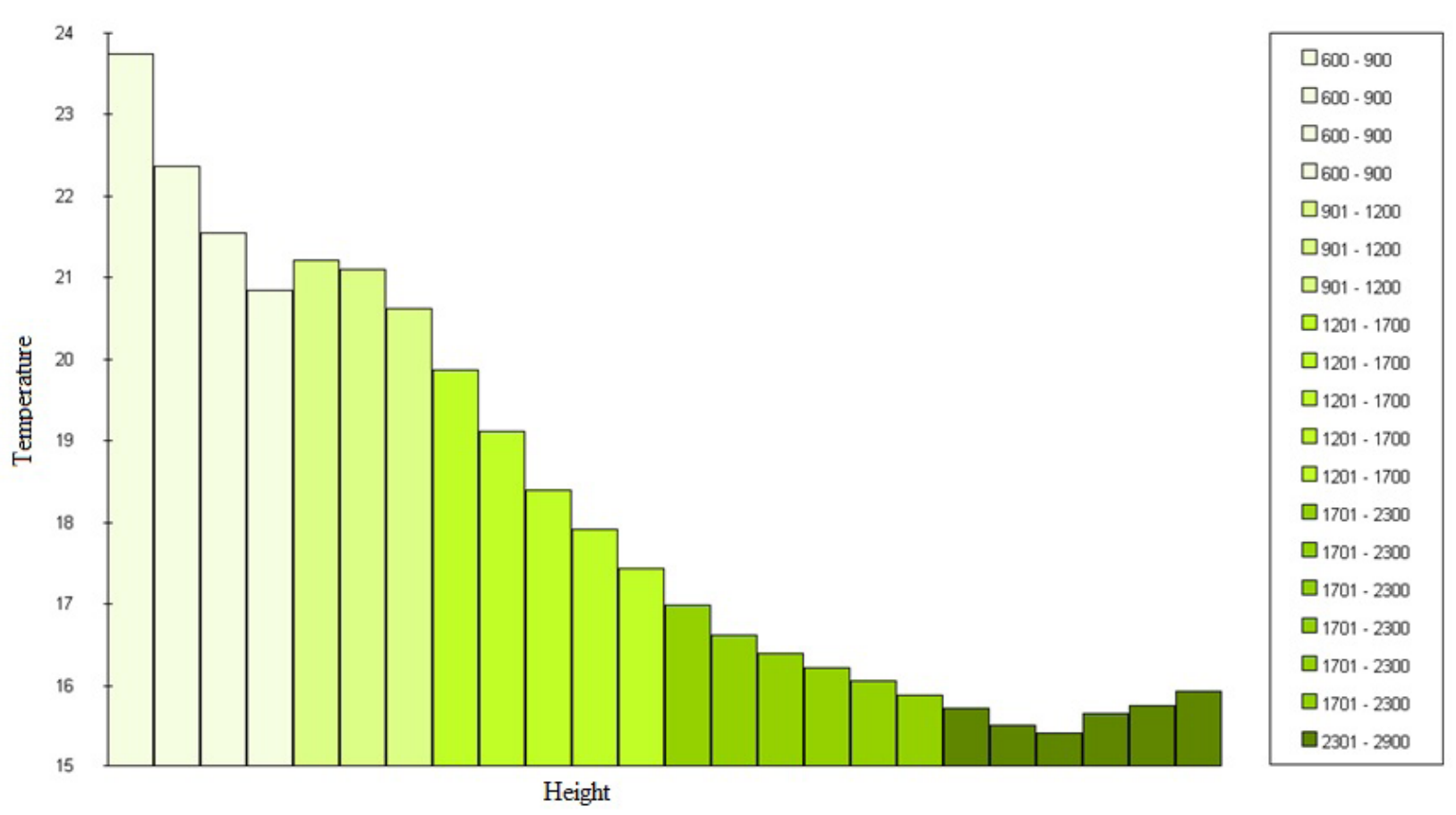

Gambar 11. Pola Perubahan Temperatur dan Ketinggian Taman Nasional Gunung Gede Pangrango

Untuk memudahkan intepretasi hubungan antara perubahan ketinggian dan temperatur, dirubah bentuk penyajian menjadi grafik batang, agar terlihat kecenderungan menurunnya nilai temperatur bersamaan menaiknya ketinggian, gambar 10 .

Dalam gambar 11, terlihat perubahan temperatur gradual yang tidak smooth dari ketinggian 600-900 m menuju pada ketinggian 900-1200 meter. Sebagai fenomena, kemungkinan adanya diskontinu perubahan kelas penggunaan lahan seperti lahan terbuka, jenis vegetasi, dan indeks kehijauan wilayah tersebut. Di puncak gunung pada ketinggian 2800 meter, nilai temperatur berkisar $14^{\circ} \mathrm{C}$ sampai dengan $16^{\circ} \mathrm{C}$, fenomena yang lain terdapat nilai temperatur antara $18^{\circ} \mathrm{C}$ sampai dengan $23^{\circ} \mathrm{C}$, ini di karenakan ada kelas penggunaan lahan yaitu rawa kawah gunung.

\section{SIMPULAN}

Pengetahuan tentang suhu permukaan tanah (LST) gunung sangat penting, karena membantu untuk memahami proses seperti pertukaran energi antara permukaan dan atmosfer, kebutuhan air di tanah pertanian, pengendalian dan pencegahan kebakaran dan evolusi perubahan iklim.. Perlunya formula koreksi radiometrik yang dapat menghilangkan noise, yang hasilnya mendekati kondisi sebenarnya. Perhitungan temperatur perlu melibatkan kelas penggunaan lahan, agar tidak terdapat anomali dan kerancuan dalam menetapkan nilai temperatur. Perlunya dilakukan visualisasi 3(tiga) dimensi dalam penyajian temperatur dan ketinggian, agar memudahkan pengguna memanfaatkan informasi ini. Formulasi ini cukup dapat digunakan sebagai perangkat pendukung bagi 
pengguna yang akan melakukan pendakian di Taman Nasional Gunung Gede Pangrango.

Faktor penting, agar diperoleh temperatur dengan akurasi yang cukup, yang memperhitungkan: kondisi lingkungan sekitarnya pada permukaan dan emisivitas sendiri. Untuk harus dilakukan koreksi: koreksi atmosfer untuk menghilangkan kontribusinya terhadap pengukuran satelit dan karena efek dari emisivitas permukaan.

\section{DAFTAR PUSTAKA}

(1) (Journal Online Sources style) Benyamin Dendang, "The Diversity of Butterflies in Selabintana Resort, Gunung Gede Pangrango National Park, West Java,", Balai Penelitian Kehutanan Ciamis, Jl. Raya CiamisBanjar Km. 4 PO. BOX. 5 Ciamis 46201 Telp. (0265) 771352, Fax (0265) 775866, http://www.fordamof.org/files/3_Benyamin_klm.pdf

(2) ..., Hiking in Mt Gede Pangrango National Park [0nline], http:// g ed e pangrango.org/w p content/uploads/2008/05/ hikingleaflet2007sepeng-fin.pdf

(3) (Journal Online Sources style) Javed Mallick, Yogesh Kant1 and B.D.Bharath1, Estimation of land surface temperature over Delhi using Landsat-7 ETM, GIS Department, STC-IT-CFS-GIS, Saudi Telecom, Saudi Arabia Indian Institute of Remote Sensing (NRSA), Dept. of Space, Govt. of India, J. Ind. Geophys. Union ( July 2008 ) Vol.12, No.3, pp.131-140
(4) Calvet, J.-C., A. Chanzy, and J.-P. Wigneron, Surface temperature and soil moisture retrieval in the Sahel from multiple frequency radiometry, IEEE Trans. Geosci. Remote Sens., 34, $588-600,1996$

(5) J.-F. Wang, R.-H. Zhang, R. R. Gillies, Y. Xue, , and Y.-C. Bo, Air temperature retrieval from remote sensing data based on thermodynamics, Published online October 14, 2004 \# SpringerVerlag 2004

(6) Cristóbal, J., M. Ninyerola, and X. Pons. 2008. Modeling air temperature through a combination of remote sensing and GIS data. Journal of Geophysical Research 113. D13106. doi: 10.1029/2007JD009318.

(7) E. Ozelkana, I. Papilaa, D.Z. Uca Avcia,, M. Karamana, Drought Determination By Using Land Surface Temperature And Normalized Difference Vegetation Index Istanbul Technical University, Center For Satellite Communications And Remote Sensing, Ayazaga Campus, Maslak, Istanbul. (Emre, Papila, Damla, Muhittin)@Cscrs.Itu.Edu.Tr 